\title{
Content Analysis of International Standards for Human Factors in Ship Design and Operation
}

\author{
Farizha Ibrahim, Mohd Norsyarizad Razali, Noh Zainal Abidin
}

Human-related factors account for more than $80 \%$ of accidents at sea, based on studies. According to Global Claims Review 2017 released by Allianz Global Corporate \& Specialty, an estimated $75-96 \%$ of shipping accidents have a high probability of involving human error (AGCS, 2017). Designs that do not meet human factors' needs play a significant role in contributing to human error. Documents in terms of design standards and guidelines, rules, and laws are analyzed. As a result, several documents related to human factors have been identified. These documents are based on whether to implement it, even if some are prescriptive, and others are mandatory, being published at different enforcement levels. In ensuring the consistent implementation of human factors, regulators and authorities need to take stricter measures in all the processes involved in designing and building such ships.

\section{KEY WORDS}

$\sim$ Human Factor, Ship Design

$\sim$ American Bureau of Shipping (ABS)

$\sim$ Lloyd's Register (LR)

$\sim$ Det Noske Veritas (DNV)

$\sim$ International Organisation for Standardization (ISO)

$\sim$ International Maritime Organization (IMO)

$\sim$ American Society for Testing and Materials (ASTM)

National Defence University of Malaysia, Faculty of Science and Defence Technology, Kuala Lumpur, Malaysia

e-mail: farizha@upnm.edu.my

doi: 10.7225/toms.v10.n02.014

This work is licensed under (cc) BY

Received on: 28.06.2021/Revised on: 17.10.2021/Accepted on: 18.10.2021/Published: 21.10.2021

\section{INTRODUCTION}

This journal describes how ship design covers aspects of human factors. Generally, 75-96\% of shipping accidents have a high probability of human error (AGCS, 2017; McAfferty \& Baker, 2006). This study aims to enhance appreciation of the cause of maritime accidents in terms of the role of human factors.

Results from poor management, maintenance of faults, incorrect installation, imperfect design, and the system's weaknesses are factors that tend to make the user a victim (Muschara, 2017). Therefore, user-centred design is vital in integrating non-engineering design disciplines into marine engineering during building of ships (Ahola, Murto \& Mallam, 2018).

Human factor elements are on the bottom of interest in Corporate social responsibility (CSR) for the top 15 shipping companies, which control $80 \%$ global container shipping market, even though it is an exciting issue (Tang \& Gekara, 2020). Imposing disciplinary action on any accidents at work, giving speeches and encouragement to work more safely, adding manuals or written procedures, or providing additional training will not overcome human errors caused by weaknesses in workplace design (Dekker, 2017; Ross, 2017). To find out the design is human friendly and good, three methods can be used:

Accepting the design, the rules and regulations set by such an organization must comply with ship design. Ross also identified the rules and standards appropriate to ship design, such as hull shape, structure, engine, machine interface with human and general arrangement (Papanikolaou et al., 2019).

Relevant human factors literature was studied, and the ship design model was discovered using reference analysis. In addition, relevant codes, regulations, laws, and guidelines were 


\section{Method}

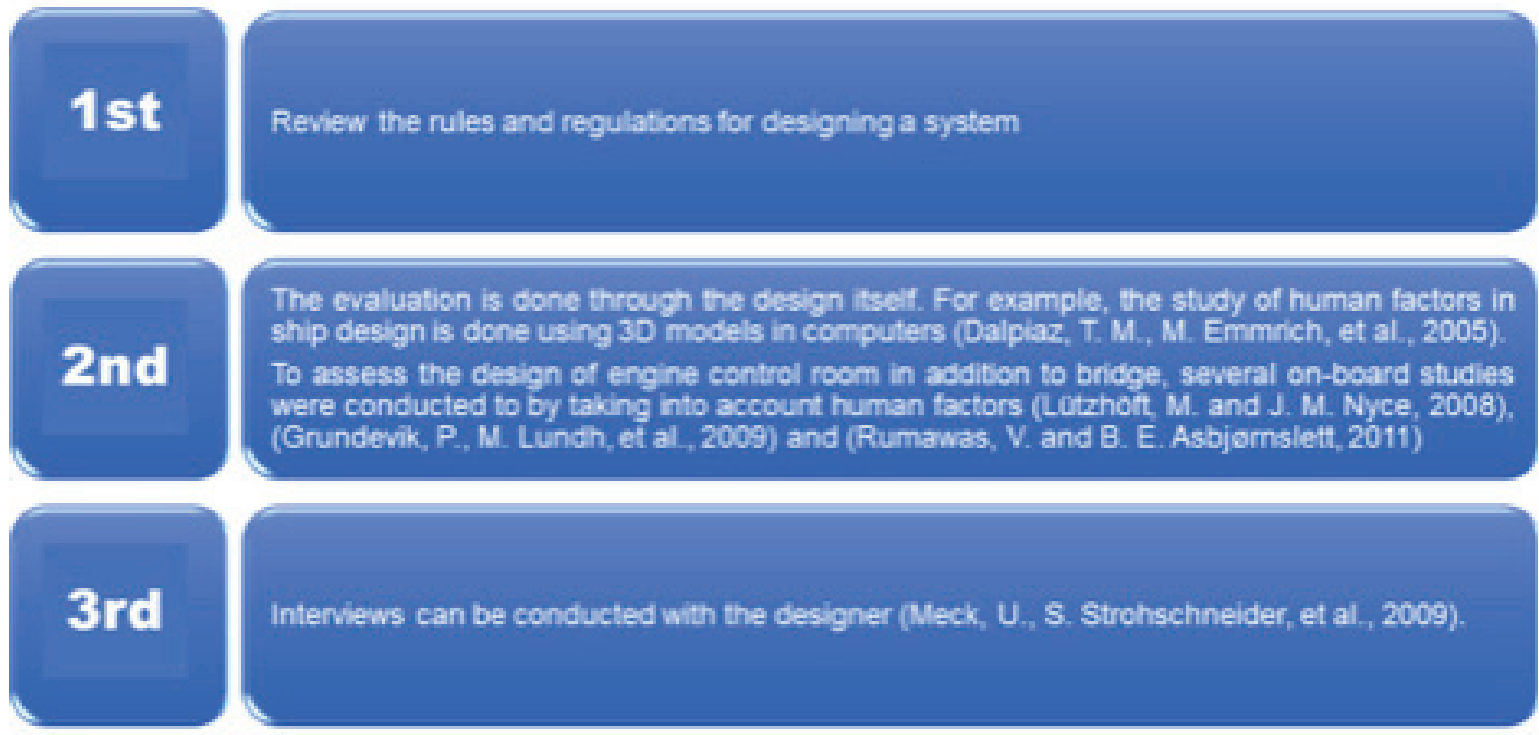

Figure 1.

Method to Measure Human Factors on Board Ships.

reviewed. The aim is to examine how human factors guidelines are provided and what things to discuss. The findings can be helpful for those engaged in ship construction and attentive in incorporating human-factors-related concepts in their design.

\section{BACKGROUND AND RELATED WORKS}

In this literature review, the human factor principle in ship design are established. It begins with the definition of the human factor from the investigated shipping community. Then, the ship planning stage is addressed. Finally, in the construction of ships, the application of the human element must be taken into consideration.

The word 'human element' for human factors is used and described by the International Maritime Organization (IMO, 2004) as "All aspects of human activities carried out by lawmakers, ship crews, shipyards, recognized organizations, regulatory bodies, land management, and other related parties involved in the human factor."

Human Factors and Ergonomics Society (HFES) defines human factor as "Applications related to what we understand about humans, the work they do, the environment in which they work, the characteristics and limitations of the equipment design they use and their capabilities are emphasized in the Human factor" (2020).
The human factor is also defined by The International Ergonomics Association (IEA, 2020) as "Emphasis on understanding the relationship between humans and other systems through scientific discipline that applies methods to design, data, principles, and theories, with the purpose of overall the system performance itself and optimize human wellbeing."

\subsection{Ship Design Process}

Ship designing is a lengthy and interrelated process, separated into several phases or stages. The design process involves developing needs, performing analysis, developing sketches and plans, building electronic models, and developing written specifications.

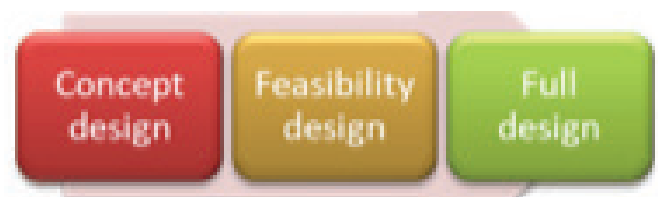

Figure 2.

Three major ships design process. 
Current developments influence the method of dividing and naming the three major ship development processes (Trincas et al., 2018). It has later distinguished the two stages of ship design depicted in Figure 3 (Andrews, 2018):

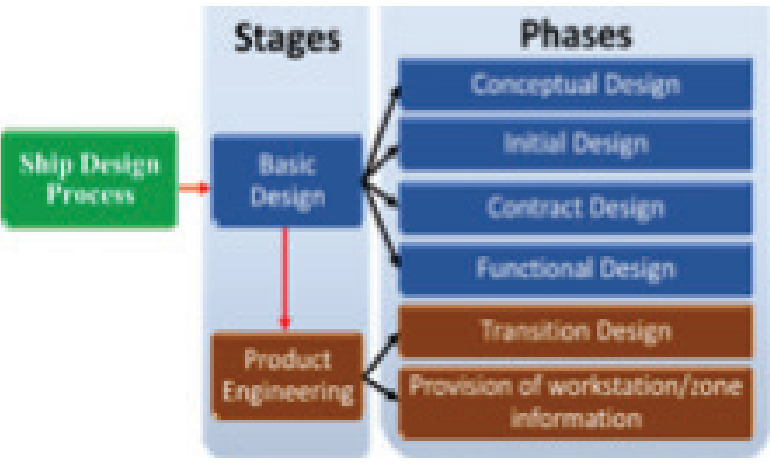

Figure 3.

Two stages of ship design.

The ship design process is divided into four phases in the book "Ship Design and Construction Textbook", as shown in Figure 4 (Papanikolaou, 2019).

The first step in this process is the mission statement, such as the area it will operate in and the type of ship to be built based on its operational nature. The longer this process, the more detailed the problems identified, e.g. HVAC diagram as well as an equipment list, installation diagram, electrical equipment, accommodation arrangement, pipe, machinery room, and machinery control room design, bridge design, ship layout, the type of machine to be installed, the type of hull to be used and the dimensions of the ship.

Any of the subjects discussed above are typical marinebased concerns, and not all issues are relevant to human factors, but may still affect their work efficiency, effectiveness, and safety.

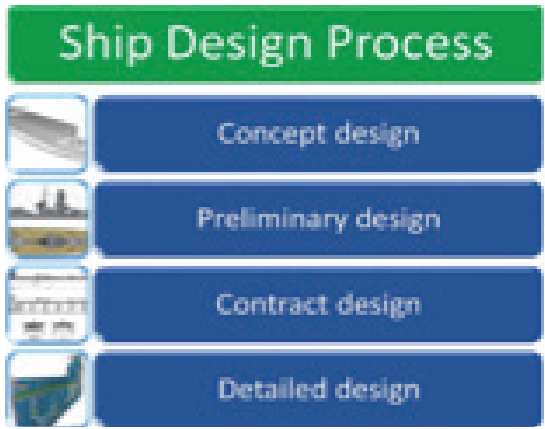

Figure 4.

Four-phase ship design process.

\subsection{Human Factors in Ship Design}

From acquisition until disposal, people are interested in a ship's life cycle. This process involves founders, architectsdesigners, registration boards, regulatory agencies, shipbuilders, manufacturers, managers/ operators of ships, sailors/unions, and insurers (Tang \& Gekara, 2020). They all have distinct yet critical impacts on protection, productivity, and effectiveness. In addition, all regulatory authorities play a significant function and can have an extensive safety effect.

The maritime administration's role, serving as the national controller of the ship's flag, is to ensure conformity with the regulations (Xaßißa, 2019). The classification authority shall set criteria and technical rules. However, they still must guarantee that the building and specifications are up to par. The designation authority has been traditional to conduct regulator roles as the flag state. Much of this information is stipulated in the specifications and recommendations that prioritize human factors to reduce design costs.

According to Rawson and Tupper, the human aspect in architecture is protected by a team with vast knowledge and experience, such as psychologists, physiologists, mechanics, and physicists who make up the squad. This human-factors team will inform engineers about how to build structures or facilities. As a result, individuals can execute activities more reliably, increase machine quality, improve human output, and have an eventual degree of environmental parameters (Trincas et al., 2018).

In a ship design and construction book published by the SNAME (Society of Naval Architects and Marine Engineers), human factor is considered as a descriptive concept encompassing all facets of the system's biomedical and psychological considerations that occur to humans. Human factors are often listed, including life support and human engineering, worker's selection, facilities for training and preparation, job equipment, as well as achievement assessment and appraisal. Human factor engineering is separately specified in ship construction. Human factor engineering incorporates strategies to assess the role of humans in dynamic environments, simulation, and modelling of human resources reduction, crew workloads, assessment of workloads for operator/maintenance, decision-making tools to minimize human error and injuries, to increase human efficiency and protection and advanced human-machine interfaces, as well as approaches and data for ship design (Charlton \& O'Brien, 2019).

Lloyd's Register (LR) identifies human variables as relevant to the activities they undertake and the context in which they operate (Lloyd's register, 2008). The word human factor signifies, as used for the construction, the function of a ship and its structures, taking human ability, expertise, weaknesses, needs into account and human usage as part of the system. The human factor describes the work environment's analysis and design 
for the value of protection, performance, productivity, health, and comfort. Shipyards, equipment control rooms, galleys, and elements relevant to work processes and procedures provide work conditions. For any ship to run safely and efficiently, it must be built to serve the persons on board without risking their wellbeing, protection, and efficiency.

In ship design, nine human factors describe motion, vision, sound, climate, safety and health, human-machine interface (Charlton and O'Brien, 2019). Concerning human factors, LR consistently identifies many different concept qualities. This concept involves the following (Lloyd's register, 2008):

Habitability - is the availability of sufficient and convenient living space, including furniture and laundry services, galleys, and room for leisure. In terms of scale, form, gender, and different environmental pressures, such as noise, heat, and vibration, this provision must consider multiple marine differences.

Maintenance - arranging the production of maintenance activities to be fast, secure, and practical, enabling systems and equipment to reach a defined standard of achievement. It involves entry concerns, removing paths, instruments, skills, disposal, and lifetime help.

Workability - customers, activities, facilities (including some software), material, processes, and the physical and social setting.

Controllability - planning the layout of ship control centres, machinery control spaces, freight control rooms, considering the integration of personnel and facilities, devices and interfaces, such as contact equipment, monitors, screens, computer stations, video monitoring units, and alarms.

Manoeuvrability - has suitable manoeuvrability for the ship's position and operating ability, including the propulsion systems, steering arrangements, including the output of shaft arrangements.

Survivability - is the fire protection facilities, damage management, and life-saving provision.

\section{METHODOLOGY}

Systematic literature review methods such as reference analysis are needed to determine how human factors are accepted in ship design, such as regulations, rules, specifications, and recommendations.

\subsection{Content Analysis}

Content analysis is a study tool to draw inferences that can be copied and checked in the sense of its usage from available models or data (Cohen et al., 2017). Neuendorf, Leedy \& Omron characterize content analysis as a comprehensive, systematic, thorough evaluation and explanation of relevant literature to find trends, meanings, prejudices, and themes (Kyngäs, 2020). In a quantitative study, the content analysis may be implemented deductively, resulting in groups' frequency of previously chosen values or values relevant to particular variables (Heidi, 2008). In order to respond to the problems in this report, this approach is considered essential. Thus, the study of material can be seen as an observation of organized and quantitative literature to see how human factors are considered in constructing ship designs and systems.

To date, there is no systematic taxonomy available in the maritime domain about human factors. LR gives the three structures the best rational and detailed framework, thus used as the fundamental framework (Lloyd's register, 2009). Measurements for coding purposes are defined and named as eight construction characteristics, as depicted in Figure 4.

Several components and facets are defined under each dimension. It realized that the system does not always follow the concept of mutually exclusive and complete code sheet development; overlap exists, and certain elements are contradictory in classifying components or aspects. Table 1, which generates the original code sheet along with the method of coding, is presented.

A code sheet was developed based on the formation of the human factor principle of ship construction. Its formation is very fluid and multi-dimensional, as depicted in Table 1.

\begin{tabular}{|l|}
\hline \multicolumn{1}{|c|}{ L.R Construetion Characteristies } \\
\hline Habitability (HAB) \\
Maintainability (MAN) \\
Workability (WORK) \\
Controllability (CONT) \\
Manoeuvrability (MANV) \\
Survival (SURV) \\
Oecupational Health and Safety (OHS) \\
System Safety (SS) \\
\hline
\end{tabular}

Figure 5.

The LR eight construction characteristics.

\subsection{Sample and Limitation}

To illustrate the coverage of human factors in ship construction, several papers can be discussed. First, a textbook and a ship construction guidebook, as seen above in section II. A (Human Factors in Ship Design) is a credible source. Next, a significant knowledge source would be published newspapers, meeting articles, studies, bulletins, and magazines. Furthermore, the recommended protocols, criteria, laws, instructions, and 
procedures issued by the classification agencies are the last listed, but most important. Since they are liable for classifying ships, the classification agencies' publications may authentically portray the industry's reality.

This study focuses on construction using an international standard system. Research population identified as records, rules, regulations, or guidance provided by the related classification agencies and foreign agencies regulating certain aspects of ship design may influence human efficiency, health, or safety on board. In the study, three prominent classification organizations as samples: Det Norske Veritas (DNV), Lloyd's Register (LR), and the American Bureau of Shipping (ABS) and China Classification Society (CCS). In addition, the following organizations also have been sampled, which is ASTM, IMO, and ISO.

According to the level of research facility, only two data discovery stages were conducted. First, a detailed survey brings the list of publications in each source in the first instance. At this point, the document's title is determined. Next, a thorough reference review is conducted on each chosen document by applying a predefined code sheet covering keywords relevant to human factors.

\subsection{Society for Classification}

The three primary classification societies, DNV, LR, and ABS, constitute a large part of the ship classification sector and are significantly involved in the human factors considered in maritime architecture. This analysis also will include CCS due to its importance in shipping classification and acceptance by 55 major global shipping countries.

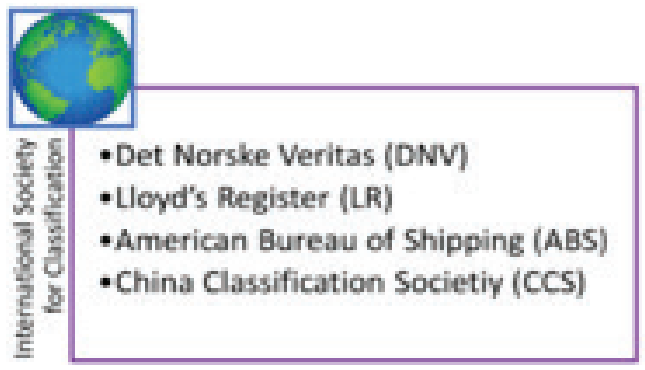

Figure 6.

Classification Societies.

Table 1.

Code sheet.

\begin{tabular}{lll} 
Dimension & Component & Aspect / object \\
\hline Habitability (HAB) & Accommodation & $\begin{array}{l}\text { Galleys, Mess } \\
\text { Recreational Space } \\
\text { Cabin }\end{array}$ \\
& & Size \\
& Crew Variant & Shape \\
& & Gender \\
\hline
\end{tabular}

Environment Pressure

Surrounding Condition

Indoor Climate

Comfort, Noise, Sound

Heat, Temperature

Air Speed, Ventilation

Air quality, smell

Ship Motion

Vibration

Lighting

Maintainability (MAIN) Maintenance Task

Layouts, Entrance, Exit

Equipments

Specialist

Disposal

Lifelong Support 


\begin{tabular}{|c|c|c|}
\hline Workability (WORK) & $\begin{array}{l}\text { Users } \\
\text { Assignment } \\
\text { Equipment and Software } \\
\text { Material \& procedure } \\
\text { Physical and Social } \\
\text { Environment }\end{array}$ & $\begin{array}{l}\text { Accessibility } \\
\text { Arrangement } \\
\text { Space }\end{array}$ \\
\hline \multirow[t]{2}{*}{ Controllability (CONT) } & Control Center & $\begin{array}{l}\text { Bridge } \\
\text { Engine Control Room } \\
\text { Combat Information Center }\end{array}$ \\
\hline & $\begin{array}{l}\text { System-Crew } \\
\text { Integration } \\
\text { Man-machine Interface }\end{array}$ & $\begin{array}{l}\text { Communication Equipment } \\
\text { Swicth and Control } \\
\text { Display, video display unit } \\
\text { Alarm } \\
\text { Autamation } \\
\text { Computer Station }\end{array}$ \\
\hline Manoeuvrability (MANV) & $\begin{array}{l}\text { Propulsion System } \\
\text { Steering System } \\
\text { Thrust }\end{array}$ & \\
\hline Survivability (SURV) & $\begin{array}{l}\text { Fire Fighting } \\
\text { Damage Control } \\
\text { Life Saving Equipments }\end{array}$ & \\
\hline Occupational Health and Safety (OHS) & $\begin{array}{l}\text { Impact on Work } \\
\text { Working Environment } \\
\text { Accomodation Condition }\end{array}$ & \\
\hline System safety (SS) & Risk Assessment & \\
\hline
\end{tabular}

A few recommendations are presented by ABS covering problems relevant to human factors and include supplementary notes such as HAB and COMF. DNV gives extra COMF notation. In addition to the laws and regulations, LR includes CEPAC notation and allows much effort.

The four global major classification bodies are the Det Norske Veritas (DNV), Lloyd's Register (LR), American Bureau of Shipping (ABS), and China Classification Society (CCS). They display a particular interest in the human factors in naval architecture. The ABS guides resolving human factor challenges and includes supplementary notations such as Comfort (COMF) and Habitability (HAB). The DNV gives extra COMF notation. In addition to regulations and guidelines, The LR includes the Crew and Embarked Personnel Accommodation Comfort (CEPAC) notation.

\subsubsection{Det Norske Veritas (2020)}

DNV defines the regulations and guidelines from Ship Classification Laws, High-Speed Classification Rules, Regulatory
Definition, Service Requirements, Offshore Operation Criteria, Offshore Standards, and Practices Suggested. The publications released by the DNV in Table 2 can accommodate human factors in commercial and naval vessel construction.

Not all the publications referred to in Table 2 were built on the foundation of the facets of human factors. For example, the Definition of Vibration in Part 6, Chapter 15 was rendered by considering that vibration can influence the operation of some vital equipment and machinery and cause harm to any significant arrangements. SILENT Class Notation in Chapter 24 implements the correct operation of the machinery utilized by the ship.

DNV defines the regulations and guidelines from Ship Classification Laws, High-Speed Classification Rules and Navy Ships, Regulatory Interpretation, Service Requirements, Offshore Operation Specifications, Offshore Standards, and Practices Suggested.

The publications released by the DNV in Table 3 are known to accommodate human factors in commercial and naval vessel construction. 
Table 2.

The DNV Human factors related to rules for classification of ships and vessels.

Rules for Ship Classification

\begin{tabular}{lll}
\hline Part 3 & Hull and equipment - Main Class & \\
\hline Part 4 & Ch 3 & Ship Hull and Safety Equipment \\
\hline & System and Machinery - Main Class & \\
\hline & Ch 9 & Control and Monitoring System \\
\hline Ch 10 & Fire Fighting \\
\hline Part 5 & Ch 14 & Steering Gear \\
\hline Part 6 & Special Type and Class- Additional Class & \\
\hline & Ch 12 & Comfort Class \\
\hline Special Equipment and System Class - Additional Class \\
\hline Ch 2 & Redundancy Propulsion System \\
\hline Ch 3 & Machinery Room Without Periodic \\
& Supervision \\
\hline Ch 4 & Additional Fire Protection System \\
\hline Ch 8 & Nautical Safety \\
\hline Ch 9 & Computer Systems for Longitudinal \\
& Stability and Strength \\
\hline Ch 15 & Vibration Class
\end{tabular}

Table 3.

The remaining DNV documents taking human factors into account in the design stage.

Recommended Action

\begin{tabular}{ll}
\hline A203 & New Technology Qualifications \\
\hline C205 & Environmental Conditions and Environment \\
\hline D102 & Analysis of Failure and Impact Methods of Overlapping Systems \\
\hline D201 & Dependence on Integrated Software Systems \\
\hline
\end{tabular}

\subsubsection{Lloyd's Register (2020)}

The regulations and laws are divided into two classifications by the LR: energy and maritime. There are 130 documents in the maritime division, and 25 documents in the resources category. Table 4 provides the documents from the LR applicable to ship construction, focusing on human factors. 
Table 4.

The LR documents related to human factors.

Rules and Regulations for Ship Classification

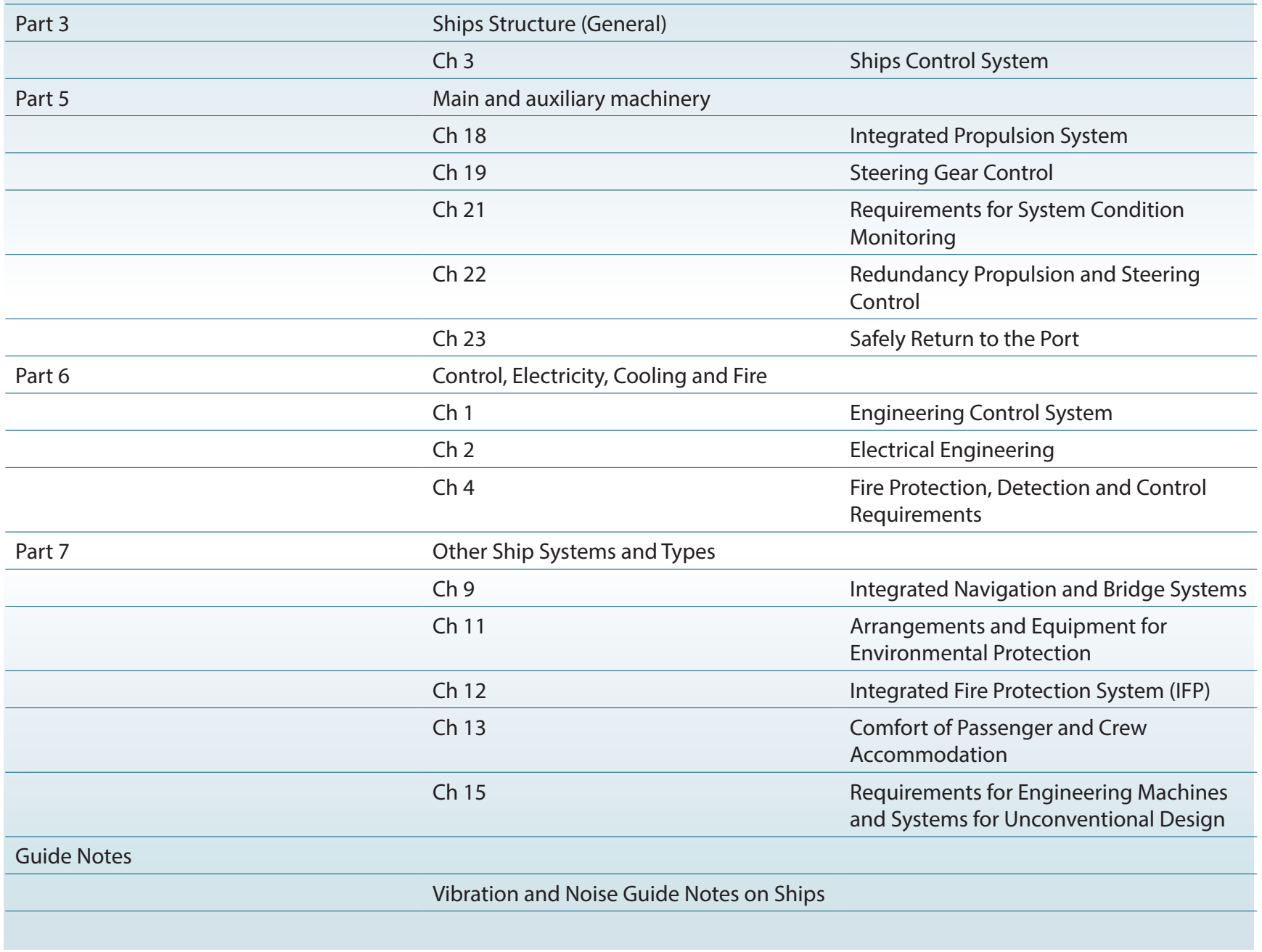

\subsubsection{The American Bureau of Shipping (2020)}

According to the ABS, 138 maritime business regulations and rules cover ships, offshore installations, floating structures, underwater vessels, machinery, parts, and products. Therefore, a total of seventeen articles in this study can be classified as targeted papers (see Table 5).

\subsubsection{China Classification Society (CCS) (2021)}

The CCS offers specific guidelines for vehicles, offshore facilities, vessels, and associated manufacturing goods and develops certification, classification and professional advisory support in an unbiased, objective, and truthful way. There are 22 papers from the CCS applicable to ship construction standards, focusing on the human factor (see Table 6). 
Table 5.

The ABS human factors in ship design rules and regulations.

\begin{tabular}{ll} 
Pub\# & Title \\
\hline 86 & Application of Ergonomics to Marine Systems \\
\hline 94 & Bridge Design and Navigational Equipment/Systems \\
\hline 97 & Risk Assessment Applications for the Marine and Offshore Oil and Gas Industries \\
\hline 102 & Crew Habitability on Ships \\
\hline 103 & Passenger Comfort on Ships \\
\hline 116 & Review and Approval of Novel Concepts \\
\hline 119 & Risk Evaluations for the Classification of Marine Related Facilities \\
\hline 112 & Ergonomic Design of Navigation Bridges \\
\hline 141 & Alternative Design and Arrangements for Fire Safety \\
\hline 145 & Fire-Fighting Systems \\
\hline 147 & Vessel Manoeuvrability \\
\hline 151 & Ship Vibration \\
\hline 163 & Vessels Operating in Low Temperature Environments \\
\hline 185 & Means of Access to Tanks and Holds for Inspection \\
\hline
\end{tabular}

\section{Table 6.}

The CCS documents on the human factor

Rules and Notations for Ship Classification

\begin{tabular}{llll}
\hline Part 2 & Chapter 2 & Section 18 & Helicopter Facilities \\
\hline Part 3 & Chapter 8 & Z-propulsion \\
\hline & Chapter 8 & Thruster \\
\hline Chapter 8 & & Controllable Pitch Propeller \\
\hline Part 4 & Chapter 8 & & Waterjet Unit \\
\hline Part 5 & Chapter 2 & Section 15 & Electrical Propulsion System \\
\hline & Chapter 2 & & Automation of Machinery Space \\
\hline Part 7 & Chapter 3 & & Machinery Centralized Control \\
\hline & Chapter 4 & & Bridge Remote Control \\
\hline & Chapter 2 & Section 2 & Life Saving Appliance \\
\hline & Chapter 2 & Section 3 & Communication Equipment \\
\hline & Chapter 2 & Section 4 & Navigation Equipment \\
\hline
\end{tabular}




\begin{tabular}{lll}
\hline \multicolumn{1}{c}{ Chapter 3} & Crew Accommodation Equipment \\
\hline Chapter 3 & Comfort (Noise) \\
\hline Chapter 3 & & Comfort (Vibration) \\
\hline Chapter 4 & Section 3 & Clean Naval Ship \\
\hline Chapter 7 & & Manoeuvrability of naval ships at sea \\
\hline Chapter 4 & & Open man Bridge Operation \\
\hline Chapter 8 & Section 3 & Refrigeration System \\
\hline Chapter 11 & & Dynamic Positioning System
\end{tabular}

\subsection{International and Industry Standards}

Three other related bodies in legislation and standardization were assessed in addition to the classification body, as presented in Figure 7.

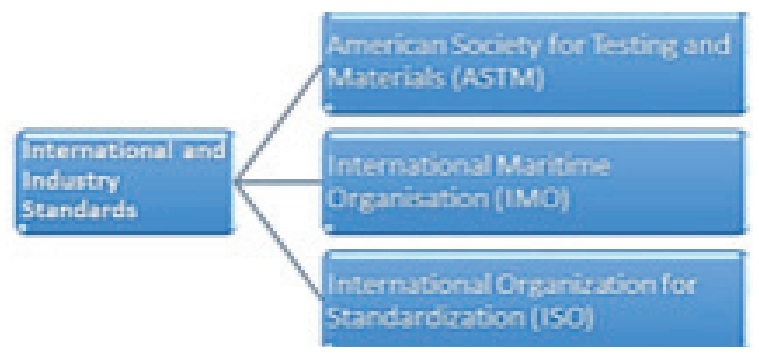

Figure 7.

International and Industry Standards.

\subsubsection{The American Society for Testing and Materials (ASTM, 2020)}

The organization by the ASTM was created referring to international principles with the consensus volunteers. In 1978, the ASTM founded a committee named F25 to create Ships and Maritime Technology Standards. Two unique norms suit the purpose of this study:

\begin{tabular}{|l|l|}
\hline F1166-07 & $\begin{array}{l}\text { Maritime Structures, Machinery, and Services } \\
\text { Standard Practices for Human Engineering } \\
\text { Architecture }\end{array}$ \\
\hline $\begin{array}{l}\text { Best Procedures for Ships and Structures, } \\
\text { Machinery, and Services Specifications for } \\
\text { the Human Engineering Program }\end{array}$ \\
\hline
\end{tabular}

Figure 8.

The ASTM unique norm covers human factor.

\subsubsection{International Maritime Organization (IMO, 2020)}

The IMO is responsible for ensuring that legislation is continuously modified to ensure that as many countries as possible ratify those regulations and fully adopt all treaties and agreements by the countries that adopt them. Human factors in ship activities link to a vast number of the IMO publications. In numerous formats, the IMO documents issues: agreements, circulars, guidelines, conventions, guides, manuals, model classes, practices, suggestions, laws, rules, and resolutions. Conventions and codes promulgated by the IMO are depicted in Figures 8 and 9.

The STCW covers the acoustic impedance on board, and applies to code and resolution as to code and convention. These codes and conventions suggest that in the IMO publication specific issues are discussed more than once.

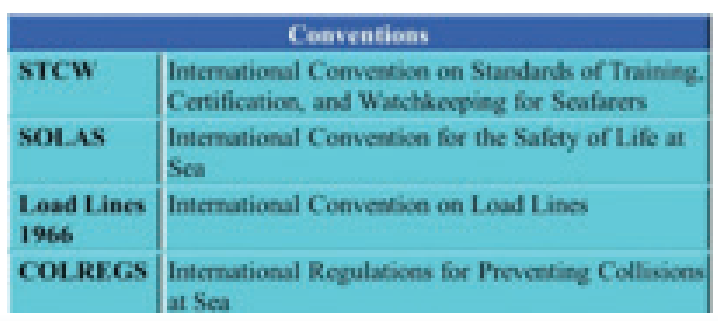

Figure 9.

The essential Conventions referring to human factor.

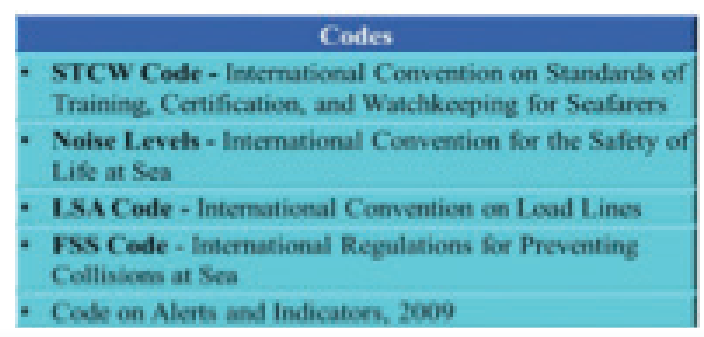

Figure 10.

The human-factors-related IMO Codes. 
Examples of other IMO publications related to human factors in ship construction include:

Table 7.

The IMO publications concerning human factors in the construction of ships.

\section{IMO Circulars, MSC Circulars}

\begin{tabular}{|c|c|}
\hline 587 & Life Saving Appliances \\
\hline 601 & Fire Protection in Machinery Spaces \\
\hline 616 & Evaluation of Free-Fall Lifeboat Launch Performance \\
\hline 645 & Guidelines for Vessels with Dynamic Positioning Systems \\
\hline 834 & Guidelines for Engine-Room Layout, Design and Arrangement \\
\hline 846 & $\begin{array}{l}\text { Guidelines on Human Element Considerations for the Design and Management of } \\
\text { Emergency Escape Arrangements on Passenger Ships }\end{array}$ \\
\hline 849 & $\begin{array}{l}\text { Guidelines for the performance, location, use and care of emergency escape breathing } \\
\text { devices (EEBD's) }\end{array}$ \\
\hline 982 & Guidelines on Ergonomic Criteria for Bridge Equipment and Layout \\
\hline 1002 & Guidelines on Alternative Design and Arrangements for Fire Safety \\
\hline \multicolumn{2}{|c|}{ Assembly Resolutions (RES) } \\
\hline A.342(IX) & Recommendation on Performance Standards for Automatic Pilots \\
\hline A.468(XII) & Code on Noise Levels on Board Ships \\
\hline A.601(15) & Provision and Display of Manoeuvring Information on Board Ships \\
\hline A.708(17) & Navigation Bridge Visibility and Functions \\
\hline A.817(19) & Performance Standards for Electronic Chart Display and Information Systems (ECDIS) \\
\hline A.861(20) & Performance Standards for Shipborne Voyage Data Recorders (VDRs) \\
\hline A.947(23) & Human Element Vision, Principles and Goals for the Organization \\
\hline A.1021 (26) & Code on Alerts and Indicators \\
\hline \multicolumn{2}{|c|}{ Maritime Safety Committee (MSC) Resolution } \\
\hline $128(75)$ & Performance Standards for a Bridge Navigational Watch Alarm System (BNWAS) \\
\hline 137(76) & Standards for Ship Manoeuvrability \\
\hline 190(79) & $\begin{array}{l}\text { Performance Standards for the Presentation of Navigation-Related Information on } \\
\text { Shipborne Navigational Displays }\end{array}$ \\
\hline
\end{tabular}

\subsubsection{The International Organization for} Standardization (ISO, 2020)

The ISO creates universal principles and publishes them. The Technical Committee (TC)/Sub Committee (SC) in the International Classification for Standards (ICS), which is accountable for supplying those standards, may be used to access the ISO norm. For example, the ICS number 47 encompasses shipbuilding and marine structures standards, while TC 8 encompasses shipbuilding and marine technologies standards. In TC 159, ergonomics rules are described differently.

Documents under TC 159 exclusively include human factors represented in Figure 11. 
rule, legislation, and instructions. Clearly, "System Safety" is the most frequently stated in the paper since security has always been a big concern, whereas "Maintainability" is the most unchecked.

Table 9.

Overview of paper outcomes in ship construction, covering human factors.
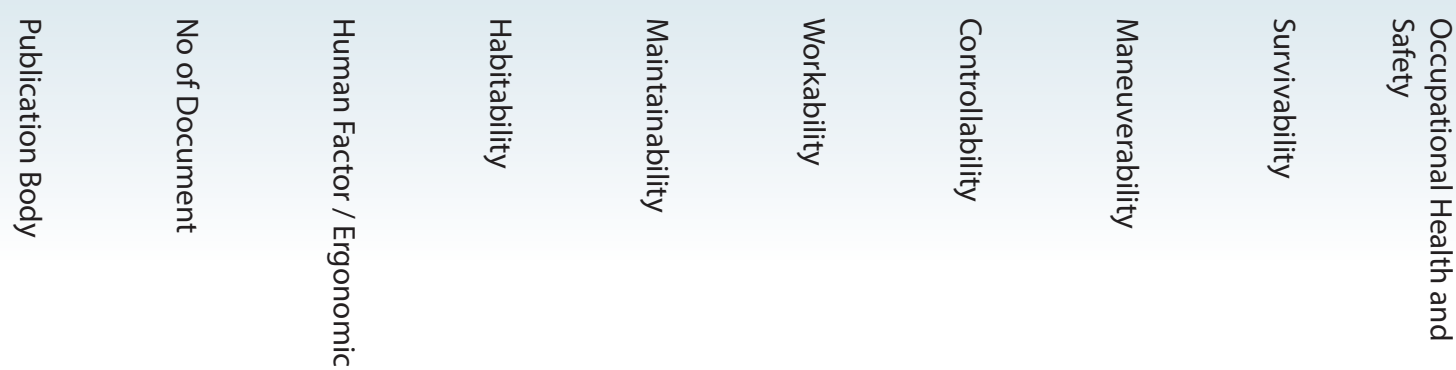

\begin{tabular}{|c|c|c|c|c|c|c|c|c|c|c|}
\hline$A B S$ & 17 & 2 & 6 & 1 & 7 & 4 & 1 & 3 & 3 & 9 \\
\hline DNV & 18 & 0 & 1 & 1 & 6 & 7 & 3 & 3 & 0 & 11 \\
\hline LR & 16 & 0 & 2 & 1 & 2 & 6 & 3 & 6 & 1 & 7 \\
\hline CCS & 22 & 3 & 2 & 2 & 7 & 10 & 7 & 1 & 3 & 7 \\
\hline IMO & 29 & 2 & 2 & 1 & 6 & 8 & 3 & 11 & 4 & 14 \\
\hline ISO (TC8) & 13 & 0 & 7 & 0 & 3 & 2 & 0 & 4 & 0 & 2 \\
\hline ASTM & 2 & 2 & 1 & 1 & 2 & 1 & 0 & 1 & 1 & 2 \\
\hline Total & 117 & 9 & 21 & 7 & 33 & 38 & 17 & 29 & 12 & 52 \\
\hline
\end{tabular}

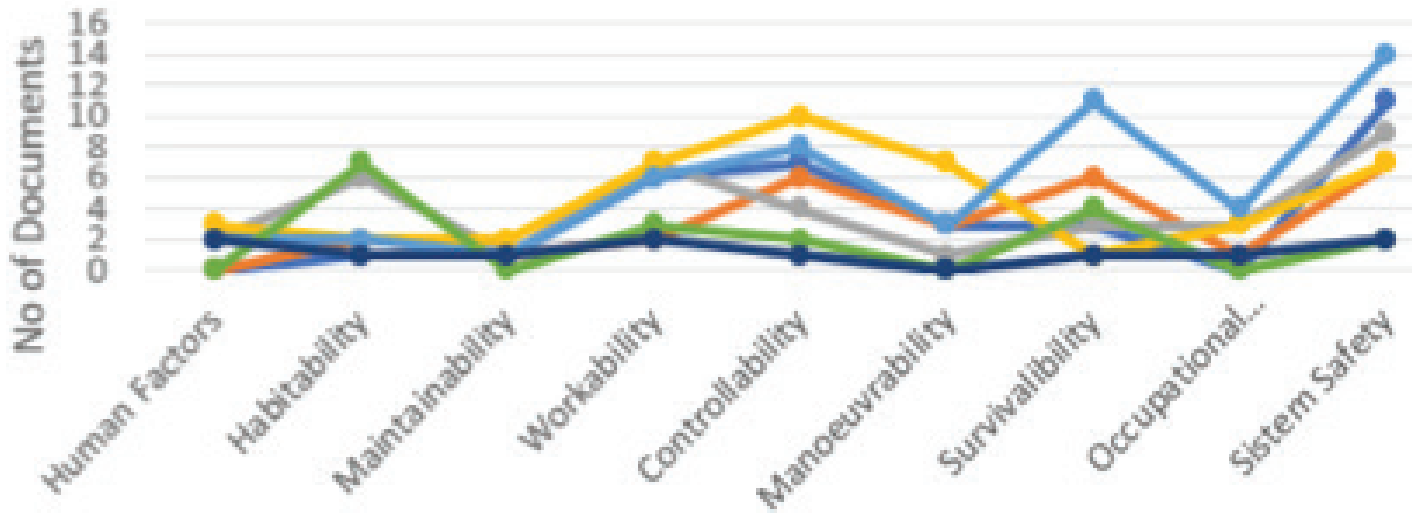

Elements of Human Factors

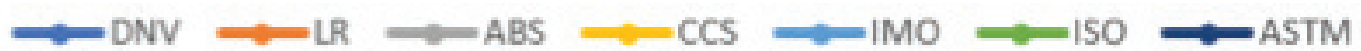

Figure 12.

Documents in ship construction, covering human factors. 
These results support Andersson's and Lützhöft's (IMO, 2004) critiques of engine control rooms' lousy nature. Meanwhile, "Survivability," "Controllability," and "Workability" include a large number of papers. "Habitability" is reasonably covered; however, as the emphasis of this review is on the "OHS" portion, not too many records cover "design".

\subsection{Study On Material}

As described, a comprehensive evaluation conduct, utilize the materials and facets of each human factors field. More elements and aspects are uncovered as the coding process continues and eventually integrated into the system, becoming a very lengthy list. As the system is created, the coding phase performs repeatedly. In the Appendix to Table A2, the final results can be seen. Any records addressing very particular subjects, such as life-saving and steering devices, fire protection software, and risk control, are not included. In ship design, the nature of human influences occupies all of these aspects. The "Workability" and "System safety" are below "Habitability."

The most widely addressed subjects of "Controllability" are sensors, control centres, workstations, buttons, and switches. These documents have clarified the fundamental problems of human factors on board. However, more complex issues emerge as simple problems are addressed. Noise, for example, is known as an onboard concern. A total of 15 records have the overall parameters of the noise level on board in this study. Among all 15 articles, the overwhelming majority does not discuss concrete concerns. The only paper describing "tonal sound" and "impulsive noise" is the ISO 2923, but it does not explain how to cope with them. The CCS also covers noise in the comfort notation in Part 7, Chapter 3, Section 7, noting the enclosure regulated at the stated sound level.

Vibration is another simple HF problem that is adequately discussed. According to this report, it has been bound by 14 records. Generally, vibration cannot be treated as an intimidating issue any more. The CCS covers vibration in the comfort notation in Part 7, Chapter 3, Section 7, noting the enclosure regulated at the stated vibration level. However, it tends to be challenging, created from certain primary forms of "vibration" (Trincas et al., 2018): ship slamming and rotation. From the aspect of human factors, one paper addresses ship motion: ISO 2631-1. This paper is the first text that separates sensations between two systems: low frequencies (for motion sickness: $<0.5 \mathrm{~Hz}$ ) and high frequencies (for wellbeing, relaxation, and perception: $>0.5 \mathrm{~Hz}$ ). The Motion Sickness Dosage Value (MSDV) accepted onboard by the ISO 2631 is applied by ABS 103 and 147. The ABS 86 deals with slamming, from all the documents surveyed in this report. $A$ common trend often appears in "alarms" protected by 14 survey records. Thus, the underlying dilemma of alarms is resolved. However, more complex alarms have been uncovered like an irrelevant number of alarms that irritate operators. Fortunately, the IMO A.1021(26) pointed out the following problems indicate how to include specific info and decrease alarms.

\section{DISCUSSION}

While different manuals have adequately discussed the problems of human factors, they are not mandatory. The standard bodies' laws and regulations are voluntary or optional, while the remainder are recommendations. The actual enforcement of human factors values relies mainly on the shipowner's devotion. Shipyards certainly play an essential function. The freight owner or the buyers and the personnel might have some feedback to make things work. However, the classification societies and the regulators should go further. Without exception, such intrinsic human conditions as noise, sound, motion, and indoor environment should be obligatory. Prospective naval architects and shipbuilders need to add some of these subjects, such as ship-human related requirements.

Three publications addressing the issue of human factors are considered to be comprehensive: the ASTM F1166, DNV Nautical Protection, and ABS 86, which have become the preferred manuals for coping with human factors in the construction of ships regardless of the flag, anywhere the ships are recorded and listed. Several problems were found in the coding sheet production stage, but have not been enclosed in any text, such as the disparities in ethnicity, disabilities, and religious differences of seafarers.

The analysis does not provide any reliability index because of inadequate resources. The reliability over time is, however, verified. Compared to the results reported earlier, this research shows that human factor involvement in ship design is increasingly evolving, represented by a growing number of published papers. Relatively stable is the trend of all the facets of human factors considered, such as disturbance, vibration, and alarms.

Concerning the least addressed problems on board, such as ship motion, i.e. slamming, smell, gender issues, and highpitch erratic noise, they are described in (Trincas et al., 2018), choosing the feature of human factors to recognize in design process through a more intelligent approach. A fast comparison with the HF reference reveals that some of the records analysed in this sample do not cover human reliability, decision-making, and social considerations.

\section{CONCLUSIONS}

Using a reference analysis approach, a literature review of other documentation has been performed. The research was conducted to discuss whether human aspects are ignored in the design and construction of ships. At least 117 publications describe 
it as essential to resolving human factors in the construction of ships, and the numbers continue to rise exponentially. It can be inferred from the analysis that human factors are not ignored in ship design specifications. 30 articles discuss it in depth. Human factors turn out to be an extensive aspect comprising several ship materials and dimensions, but their degree of coverage differs throughout the dimensions. The two dimensions often covered are protection and survivability, indicated by the overall number of papers published on the subjects. The broadest coverage is that of habitability and controllability. A more assertive intervention proposes to promote the values of human factors incorporated into ship design. The research on human factor implementation on board can be conducted using the available documents that set up the standards internationally. Performing research by questioning shipbuilders, shipyards, marine mechanics and naval architects is recommended.

\section{REFERENCES}

Ahola, M., Murto, P., \& Mallam, S., 2018. When people are the mission of a shipdesign and user research in the marine industry. Marine Design 13, pp.285-290.

Allianz Global Corporate and Specialty (AGCS), 2017. Global Claims Review: Liability In Focus.

American Bureau of Shipping, 2020. Rules and Guides Downloads. Available at: http://www.eagle.org/eagleExternalPortalWEB/appmanager/absEagle/ absEagleDesktop?_nfpb=true\&_pageLabel=abs_eagle_portal_marine_rules_ guides_download_page.

Andrews, D., 2018. The Sophistication of Early Stage Design for Complex Vessels. International Journal of Maritime Engineering, Vol 160(SE 18). Available at: http://dx.doi.org/10.3940/rina.ijme.2018.se.472.

ASTM, 2020. ASTM Overview. Available at: http://www.astm.org/ABOUT/overview. html.27.

CCS, 2021. CCS Overview. Available at: https://www.ccs.org.cn/ccswzen/.

Charlton, S.G. \& O'Brien, T.G. eds., 2019. Handbook of Human Factors Testing and Evaluation. Available at:

http://dx.doi.org/10.1201/9781003000815.

Cohen, L., Manion, L. \& Morrison, K., 2017. Coding and content analysis. Research Methods in Education, pp.668-685. Available at:

http://dx.doi.org/10.4324/9781315456539-34.

Dekker, S., 2017. The Field Guide to Human Error Investigations. Available at: http://dx.doi.org/10.4324/9781315202778.

DNV, 2020. DNV Rules and Standards. Available at: http://exchange.dnv.com/ publishing/ServiceDocs.asp.
Heidi, J., 2008. Content Analysis. Thousand Oaks, USA, SAGE Publications.

HFES, 2020. Definition of Human Factors and Ergonomics. Available at: http:// www.hfes.org/Web/EducationalResources/HFEdefinitionsmain.html, accessed on: October 2020

IMO, 2004. Human Element Vision, Principles and Goals for the Organization. A 23/ Res. 947. IMO. A.947(23).

IMO, 2020. Introduction to IMO. Available at: http://www.imo.org/About/Pages/ Default.aspx.

International Ergonomics Association, 2020. What is Ergonomics. Available at: http://www.iea.cc/01_what/What\%20is\%20Ergonomics.html.

ISO, 2020. About ISO. Available at: http://www.iso.org/iso/about.htm.

Kyngäs, H., 2019. Inductive Content Analysis. The Application of Content Analysis in Nursing Science Research, pp.13-21. Available at: http://dx.doi.org/10.1007/978-3-030-30199-6_2.

Lloyd's Register, 2008. The Human Element: An Introduction. London, Lloyd's Register.

Lloyd's Register, 2009. The Human Element Best Practice for Ship Operators. London, Lloyd's Register.

Lloyd's Register, 2020. Rules and Regulations, Leading expertise for a safer world. Available at: http://www.lr.org/sectors/marine/Compliance/RulesandRegulations. aspx.

McCafferty, D.B. et al., 2006. Trending the Causes of Marine Incidents. Learning from Marine Incidents 3. Available at:

http://dx.doi.org/10.3940/rina.mi.2006.

Muschara, T., 2017. Risk-Based Thinking. Available at: http://dx.doi.org/10.4324/9780203731734

Papanikolaou, A. ed., 2019. A Holistic Approach to Ship Design. Available at: http://dx.doi.org/10.1007/978-3-030-02810-7.

Papanikolaou, A. et al., 2019. A holistic approach to ship design: Tools and applications. In SNAME Maritime Convention.

Ross, J.M., 2017. Human Factors for Naval Marine Vehicle Design and Operation. Available at:

http://dx.doi.org/10.1201/9781315253022

Tang, L. \& Gekara, V., 2018. The Importance of Customer Expectations: An Analysis of CSR in Container Shipping. Journal of Business Ethics, 165(3), pp.383-393. Available at: http://dx.doi.org/10.1007/s10551-018-4062-4.

Trincas, G. et al., 2018. Handling the path from concept to preliminary ship design. In Marine Design 13, pp.181-191.

Xaß̌i̧a, A., 2019. The role of flag states administration in the shipping industry. Master's thesis, Пavєாıбт́́ 


\section{APPENDIX}

Document Content Analysis

\begin{tabular}{|c|c|c|c|c|c|c|c|c|c|c|c|}
\hline No & Source & ID** & 롤 & 온 & $\frac{3}{2}$ & 产 & $\frac{1}{2}$ & $\frac{3}{2}$ & 芦 & 욤 & 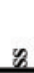 \\
\hline 1 & DNV & Pt $3 \mathrm{Ch} 3$ & 0 & 0 & 0 & 0 & 0 & 1 & 0 & 0 & 0 \\
\hline 2 & DNV & Pt 4 Ch 9 & 0 & 0 & 0 & 1 & 1 & 0 & 0 & 0 & 1 \\
\hline 3 & DNV & Pt 4 Ch 10 & 0 & 0 & 0 & 0 & 0 & 0 & 1 & 0 & 1 \\
\hline 4 & DNV & Pt 4 Ch 14 & 0 & 0 & 0 & 0 & 1 & 0 & 0 & 0 & 0 \\
\hline 5 & DNV & Pt 5 Ch 12 & 0 & 1 & 0 & 0 & 0 & 0 & 0 & 0 & 0 \\
\hline 6 & DNV & Pt $6 \mathrm{Ch} 2$ & 0 & 0 & 0 & 0 & 0 & 0 & 0 & 0 & 1 \\
\hline 7 & DNV & Pt $6 \mathrm{Ch} 3$ & 0 & 0 & 1 & 0 & 0 & 0 & 0 & 0 & 1 \\
\hline 8 & DNV & Pt $6 \mathrm{Ch} 4$ & 0 & 0 & 0 & 0 & 0 & 0 & 1 & 0 & 1 \\
\hline 9 & DNV & Pt 6 Ch 6 & 0 & 0 & 0 & 0 & 1 & 0 & 0 & 0 & 0 \\
\hline 10 & DNV & Pt $6 \mathrm{Ch} 7$ & 0 & 0 & 0 & 0 & 1 & 0 & 0 & 0 & 0 \\
\hline 11 & DNV & Pt $6 \mathrm{Ch} 8$ & 0 & 0 & 0 & 1 & 1 & 1 & 0 & 0 & 1 \\
\hline 12 & DNV & Pt 6 Ch 9 & 0 & 0 & 0 & 0 & 0 & 0 & 0 & 0 & 1 \\
\hline 13 & DNV & Pt 6 Ch 20 & 0 & 0 & 0 & 1 & 1 & 1 & 1 & 0 & 1 \\
\hline 14 & DNV & Pt 6 Ch 26 & 0 & 0 & 0 & 1 & 1 & 0 & 0 & 0 & 0 \\
\hline 15 & DNV & A203 & 0 & 0 & 0 & 1 & 0 & 0 & 0 & 0 & 1 \\
\hline 16 & DNV & $\mathrm{C} 205$ & 0 & 0 & 0 & 0 & 0 & 0 & 0 & 0 & 0 \\
\hline 17 & DNV & D102 & 0 & 0 & 0 & 0 & 0 & 0 & 0 & 0 & 1 \\
\hline \multirow[t]{2}{*}{18} & DNV & D201 & 0 & 0 & 0 & 1 & 0 & 0 & 0 & 0 & 1 \\
\hline & DNV & & 0 & 1 & 1 & 6 & 7 & 3 & 3 & 0 & 11 \\
\hline 19 & LR & Pt $3 \mathrm{Ch} 13$ & 0 & 0 & 0 & 0 & 0 & 0 & 0 & 0 & 0 \\
\hline 20 & LR & Pt $5 \mathrm{CH} 18$ & 0 & 0 & 0 & 0 & 1 & 1 & 0 & 0 & 0 \\
\hline 21 & LR & Pt $5 \mathrm{CH} 19$ & 0 & 0 & 0 & 0 & 0 & 0 & 0 & 0 & 0 \\
\hline 22 & LR & Pt 5 CH 21 & 0 & 0 & 1 & 0 & 0 & 0 & 0 & 0 & 0 \\
\hline 23 & LR & Pt 5 CH 22 & 0 & 0 & 0 & 0 & 1 & 1 & 1 & 0 & 1 \\
\hline 24 & LR & Pt 5 CH 23 & 0 & 0 & 0 & 0 & 0 & 0 & 1 & 0 & 1 \\
\hline 25 & LR & Pt $6 \mathrm{Ch} 1$ & 0 & 0 & 0 & 0 & 1 & 0 & 1 & 0 & 1 \\
\hline 26 & LR & Pt $6 \mathrm{Ch} 2$ & 0 & 0 & 0 & 0 & 1 & 1 & 1 & 0 & 1 \\
\hline 27 & LR & Pt $6 \mathrm{Ch} 4$ & 0 & 0 & 0 & 0 & 0 & 0 & 1 & 0 & 1 \\
\hline 28 & LR & Pt $6 \mathrm{Ch} 1$ & 0 & 0 & 0 & 0 & 0 & 0 & 0 & 0 & 0 \\
\hline 29 & LR & Pt $7 \mathrm{Ch} 4$ & 0 & 0 & 0 & 1 & 1 & 0 & 0 & 0 & 0 \\
\hline 30 & LR & Pt 7 Ch 9 & 0 & 0 & 0 & 1 & 1 & 0 & 0 & 0 & 0 \\
\hline 31 & LR & Pt 7 Ch 12 & 0 & 0 & 0 & 0 & 0 & 0 & 1 & 1 & 1 \\
\hline 32 & LR & Pt $7 \mathrm{Ch} 13$ & 0 & 1 & 0 & 0 & 0 & 0 & 0 & 0 & 0 \\
\hline 33 & LR & Pt 7 Ch 15 & 0 & 0 & 0 & 0 & 0 & 0 & 0 & 0 & 1 \\
\hline \multirow[t]{2}{*}{34} & LR & GN & 0 & 1 & 0 & 0 & 0 & 0 & 0 & 0 & 0 \\
\hline & LR & & 0 & 2 & 1 & 2 & 6 & 3 & 6 & 1 & 7 \\
\hline 35 & ABS & 86 & 1 & 1 & 1 & 1 & 1 & 0 & 0 & 1 & 1 \\
\hline 36 & ABS & 94 & 0 & 0 & 0 & 1 & 1 & 0 & 0 & 0 & 0 \\
\hline 37 & ABS & 97 & 0 & 0 & 0 & 0 & 0 & 0 & 0 & 0 & 1 \\
\hline 38 & ABS & 102 & 0 & 1 & 0 & 0 & 0 & 0 & 0 & 0 & 0 \\
\hline 39 & ABS & 103 & 0 & 1 & 0 & 0 & 0 & 0 & 0 & 0 & 0 \\
\hline 40 & ABS & 116 & 0 & 0 & 0 & 0 & 0 & 0 & 0 & 0 & 1 \\
\hline 41 & ABS & 117 & 0 & 0 & 0 & 0 & 0 & 0 & 0 & 0 & 1 \\
\hline 42 & ABS & 119 & 1 & 0 & 0 & 1 & 1 & 0 & 0 & 0 & 0 \\
\hline 43 & ABS & 122 & 0 & 0 & 0 & 0 & 0 & 0 & 1 & 0 & 1 \\
\hline 44 & ABS & 141 & 0 & 0 & 0 & 0 & 0 & 0 & 1 & 0 & 0 \\
\hline 45 & ABS & 145 & 0 & 0 & 0 & 0 & 0 & 1 & 0 & 0 & 0 \\
\hline 46 & ABS & 147 & 0 & 1 & 0 & 1 & 0 & 0 & 0 & 0 & 0 \\
\hline 47 & ABS & 151 & 0 & 1 & 0 & 1 & 0 & 0 & 0 & 1 & 1 \\
\hline 48 & ABS & 154 & 0 & 0 & 0 & 1 & 0 & 0 & 0 & 1 & 1 \\
\hline 49 & ABS & 163 & 0 & 1 & 0 & 0 & 0 & 0 & 0 & 0 & 0 \\
\hline 50 & ABS & 170 & 0 & 0 & 0 & 0 & 0 & 0 & 1 & 0 & 1 \\
\hline \multirow[t]{2}{*}{51} & ABS & 185 & 0 & 0 & 0 & 1 & 1 & 0 & 0 & 0 & 1 \\
\hline & ABS & & 2 & 6 & 1 & 7 & 4 & 1 & 3 & 3 & 9 \\
\hline
\end{tabular}




\begin{tabular}{|c|c|c|c|c|c|c|c|c|c|c|c|}
\hline No & Source & ID $^{* *}$ & 量 & $\mathbb{Z}$ & $\sum_{\Sigma}^{Z}$ & $\begin{array}{l}\text { है } \\
\text { ठै }\end{array}$ & 至 & Z & 菅 & 络 & $\infty$ \\
\hline 52 & $\mathrm{CCS}$ & Pt 2 Ch 2 & 0 & 0 & 0 & 1 & 0 & 0 & 0 & 0 & 1 \\
\hline 53 & CCS & Pt $3 \mathrm{Ch} 8$ & 0 & 0 & 0 & 0 & 1 & 1 & 0 & 0 & 0 \\
\hline 54 & CCS & Pt $3 \mathrm{Ch} 8$ & 0 & 0 & 0 & 0 & 1 & 0 & 0 & 0 & 0 \\
\hline 55 & CCS & Pt $3 \mathrm{Ch} 8$ & 0 & 0 & 0 & 0 & 1 & 1 & 0 & 0 & 0 \\
\hline 56 & CCS & Pt $3 \mathrm{Ch} 8$ & 0 & 0 & 1 & 0 & 0 & 0 & 0 & 0 & 0 \\
\hline 57 & CCS & Pt 4 Ch 2 & 0 & 1 & 1 & 1 & 1 & 1 & 0 & 0 & 1 \\
\hline 58 & CCS & Pt $5 \mathrm{Ch} 2$ & 0 & 0 & 0 & 1 & 1 & 0 & 0 & 0 & 1 \\
\hline 59 & CCS & Pt $5 \mathrm{Ch} 3$ & 1 & 0 & 0 & 1 & 1 & 0 & 0 & 0 & 1 \\
\hline 60 & CCS & Pt $5 \mathrm{Ch} 4$ & 1 & 0 & 0 & 1 & 1 & 1 & 0 & 0 & 1 \\
\hline 61 & CCS & $\mathrm{Pt} 7 \mathrm{Ch} 2$ & 0 & 0 & 0 & 1 & 0 & 0 & 1 & 1 & 0 \\
\hline 62 & $\mathrm{CCS}$ & Pt $7 \mathrm{Ch} 2$ & 0 & 0 & 0 & 0 & 0 & 0 & 0 & 0 & 0 \\
\hline 63 & CCS & $\mathrm{Pt} 7 \mathrm{Ch} 2$ & 0 & 0 & 0 & 0 & 1 & 1 & 0 & 0 & 0 \\
\hline 64 & CCS & Pt $7 \mathrm{Ch} 2$ & 0 & 0 & 0 & 0 & 1 & 0 & 0 & 0 & 0 \\
\hline 65 & CCS & Pt $7 \mathrm{Ch} 2$ & 0 & 0 & 0 & 0 & 0 & 0 & 0 & 0 & 0 \\
\hline 66 & $\mathrm{CCS}$ & Pt $7 \mathrm{Ch} 3$ & 1 & 1 & 0 & 0 & 0 & 0 & 0 & 1 & 0 \\
\hline 67 & CCS & $\mathrm{Pt} 7 \mathrm{Ch} 3$ & 0 & 0 & 0 & 0 & 0 & 0 & 0 & 0 & 0 \\
\hline 68 & CCS & Pt $7 \mathrm{Ch} 3$ & 0 & 0 & 0 & 0 & 0 & 0 & 0 & 0 & 0 \\
\hline 69 & $\mathrm{CCS}$ & Pt $7 \mathrm{Ch} 4$ & 0 & 0 & 0 & 0 & 0 & 0 & 0 & 1 & 0 \\
\hline 70 & CCS & Pt $7 \mathrm{Ch} 7$ & 0 & 0 & 0 & 0 & 0 & 1 & 0 & 0 & 0 \\
\hline 71 & CCS & Pt $8 \mathrm{Ch} 4$ & 0 & 0 & 0 & 1 & 0 & 1 & 0 & 0 & 0 \\
\hline 72 & $\mathrm{CCS}$ & Pt $8 \mathrm{Ch} 8$ & 0 & 0 & 0 & 0 & 0 & 0 & 0 & 0 & 1 \\
\hline \multirow[t]{2}{*}{73} & CCS & Pt 8 Ch 11 & 0 & 1 & 0 & 0 & 1 & 0 & 0 & 0 & 1 \\
\hline & CCS & & 3 & 2 & 2 & 7 & 10 & 7 & 1 & 3 & 7 \\
\hline 74 & IMO & COLREGS & 0 & 0 & 0 & 0 & 1 & 0 & 0 & 0 & 1 \\
\hline 75 & IMO & LL & 0 & 0 & 0 & 0 & 0 & 0 & 0 & 0 & 1 \\
\hline 76 & IMO & SOLAS & 0 & 0 & 0 & 0 & 0 & 0 & 0 & 0 & 1 \\
\hline 77 & IMO & STCW & 0 & 0 & 0 & 1 & 0 & 0 & 0 & 0 & 0 \\
\hline 78 & IMO & ALI & 0 & 0 & 0 & 0 & 0 & 0 & 1 & 0 & 1 \\
\hline 79 & IMO & CAI & 0 & 0 & 0 & 0 & 0 & 0 & 1 & 0 & 1 \\
\hline 80 & IMO & FSS & 0 & 0 & 0 & 0 & 0 & 0 & 1 & 0 & 1 \\
\hline 81 & IMO & LSA & 0 & 0 & 0 & 0 & 0 & 0 & 1 & 0 & 1 \\
\hline 82 & IMO & NOISE & 0 & 1 & 0 & 0 & 0 & 0 & 0 & 0 & 0 \\
\hline 83 & IMO & A 342 (IX) & 0 & 0 & 0 & 0 & 1 & 0 & 0 & 0 & 1 \\
\hline 84 & IMO & A 468 (XII) & 0 & 1 & 0 & 0 & 0 & 0 & 0 & 0 & 0 \\
\hline 85 & IMO & A 601 (15) & 0 & 0 & 0 & 0 & 0 & 1 & 0 & 0 & 0 \\
\hline 86 & IMO & A 708 (17) & 0 & 0 & 0 & 0 & 1 & & 0 & 0 & 0 \\
\hline 87 & IMO & A 817 (19) & 0 & 0 & 0 & 1 & 1 & 1 & 0 & 0 & 0 \\
\hline 88 & IMO & A 830 (19) & 0 & 0 & 0 & 0 & 0 & 0 & 0 & 0 & 0 \\
\hline 89 & IMO & A $861(20)$ & 0 & 0 & 0 & 0 & 0 & 0 & 0 & 0 & 1 \\
\hline 90 & IMO & A 947 (23) & 1 & 0 & 0 & 0 & 0 & 0 & 0 & 0 & 0 \\
\hline 91 & IMO & Res $128(75)$ & 0 & 0 & 0 & 0 & 0 & 0 & 1 & 1 & 1 \\
\hline 92 & IMO & Res $137(76)$ & 0 & 0 & 0 & 0 & 0 & 1 & 0 & 0 & 0 \\
\hline 93 & IMO & Res $190(79)$ & 0 & 0 & 0 & 1 & 1 & 0 & 0 & 0 & 0 \\
\hline 94 & IMO & Circ 587 & 0 & 0 & 0 & 0 & 0 & 0 & 0 & 0 & 0 \\
\hline 95 & IMO & Circ 601 & 0 & 0 & 0 & 0 & 0 & 0 & 1 & 0 & 1 \\
\hline 96 & IMO & Circ 616 & 0 & 0 & 0 & 0 & 0 & 0 & 1 & 0 & 1 \\
\hline 97 & IMO & Circ 645 & 0 & 0 & 0 & 1 & 1 & 0 & 0 & 0 & 0 \\
\hline 98 & IMO & Circ 834 & 0 & 0 & 1 & 1 & 1 & 0 & 1 & 1 & 1 \\
\hline 99 & IMO & Circ 846 & 0 & 0 & 0 & 0 & 0 & 0 & 1 & 0 & 0 \\
\hline 100 & IMO & Circ 849 & 0 & 0 & 0 & 0 & 0 & 0 & 1 & 1 & 0 \\
\hline 101 & IMO & Circ 982 & 1 & 0 & 0 & 1 & 1 & 0 & 0 & 0 & 0 \\
\hline 102 & IMO & Circ 1002 & 0 & 0 & 0 & 0 & 0 & 0 & 1 & 0 & 1 \\
\hline
\end{tabular}




\begin{tabular}{|c|c|c|c|c|c|c|c|c|c|c|c|}
\hline & IMO & & 2 & 2 & 1 & 6 & 8 & 3 & 11 & 3 & 14 \\
\hline 101 & ISO & 2631-1:1997 & 0 & 1 & 0 & 0 & 0 & 0 & 0 & 0 & 0 \\
\hline 102 & ISO & 2923:1996 & 0 & 1 & 0 & 0 & 0 & 0 & 0 & 0 & 0 \\
\hline 103 & ISO & $3797: 1976$ & 0 & 0 & 0 & 1 & 0 & 0 & 0 & 0 & 0 \\
\hline 104 & ISO & $5488: 1979$ & 0 & 1 & 0 & 0 & 0 & 0 & 0 & 0 & 0 \\
\hline 105 & ISO & 5489:2008 & 0 & 1 & 0 & 0 & 0 & 0 & 1 & 0 & 0 \\
\hline 106 & ISO & $6954: 2000$ & 0 & 1 & 0 & 0 & 0 & 0 & 0 & 0 & 0 \\
\hline 107 & ISO & $17631: 2002$ & 0 & 0 & 0 & 0 & 0 & 0 & 1 & 0 & 1 \\
\hline 108 & ISO & 20283-2:2008 & 0 & 1 & 0 & 0 & 0 & 0 & 0 & 0 & 0 \\
\hline 109 & ISO & $20283-4$ & 0 & 1 & 0 & 1 & 1 & 0 & 0 & 0 & 0 \\
\hline 110 & ISO & $24409-1: 2010$ & 0 & 0 & 0 & 0 & 0 & 0 & 1 & 0 & 1 \\
\hline 111 & ISO & 27991:2008 & 0 & 0 & 0 & 0 & 0 & 0 & 1 & 0 & 0 \\
\hline 112 & ISO & $8468: 2007$ & 0 & 0 & 0 & 1 & 0 & 0 & 0 & 0 & 0 \\
\hline \multirow[t]{2}{*}{113} & ISO & 2412:1982 & 0 & 0 & 0 & 0 & 1 & 0 & 0 & 0 & 0 \\
\hline & ISO & & $\overline{0}$ & 7 & $\overline{0}$ & 3 & 2 & $\overline{0}$ & 4 & $\overline{0}$ & 2 \\
\hline 114 & $\overline{\text { ASTM }}$ & F1166-07 & 1 & 1 & 1 & 1 & 1 & 0 & 1 & 1 & 1 \\
\hline \multirow[t]{2}{*}{115} & ASTM & F1337-10 & 1 & 0 & 0 & 1 & 0 & 0 & 0 & 0 & 1 \\
\hline & ASTM & & 2 & 1 & 1 & 2 & 1 & 0 & 1 & 1 & 2 \\
\hline
\end{tabular}

